\title{
S40. Anxiolytic drugs
}

POTENTIAL SIGNIFICANCE OF CCK-B RECEPTORS AND CCK-B ANTAGONISTS IN PANIC DISORDER.

J.A. Den Boer, H.J.G.M. van Megen, H.G.M Westenberg. Department of Psychiatry, P.O Box 85500, 3508GA, Utrecht, The Netherlands.

An increasing body of evidence suggest that CCK-B receptors are involved in biological processes that regulate anxiety. Previous investigations revealed that $\mathrm{CCK}-4$ and the $\mathrm{CCK}-4$ analogue pentagastrin are able to induce panic attacks in patients with panic disorder (PD). Advantages of administration of CCK-4 in the provocation of panic are: 1) that it rapidly induced panic which lasts only about 2 minutes and 2) the point of panic is relatively easily to define, compared with other challenge paradigms (e.g. lactate)

In the present studies we investigated the ability of the CCK-B receptor antagonists L-365,260 and CI-988 to block CCK-4 induced panic. Methods: In two double-blind studies using an unbalanced incomplete block design we compared the effects of placebo, and the CCK-B receptor antagonists L,365,260 and CI-988 on panic attacks induced by CCK-4. PD patients were treated with either placebo or 10 or $50 \mathrm{mg} \mathrm{L}-365,260$ before receiving an i.v. bolusinjection of $20 \mu \mathrm{g} \mathrm{CCK}-$ 4. In the case of CI-988, before being injected with an i.v. bolus injection of $20 \mu \mathrm{g} \mathrm{CCK}-4$ patients received either a) two placebo capsules b) $50 \mathrm{mg} \mathrm{Cl}-988$ or c) $100 \mathrm{mg}$ CI-988. Results: The level of anxiety and panic were measured with a Visual Analogue Scale and the Panic Symptom Scale respectively. Pretreatment with placebo produced panic attacks in $86 \%$ of the patients, whereas pretreatment with L-365,260 led to a dose dependent statistically significant reduction in panic attacks. The panic rate was $33 \%$ for $10 \mathrm{mg}$ of $\mathrm{L}-365,260$ and $0 \%$ for $50 \mathrm{mg} \mathrm{L}-365,260$. The experiments with CI-988 yielded similar results. Conclusion: 1) Stimulation of CCK-B receptors provides a reliable method to provoke panic attacks in a clinical population of PD patients. 2) This panic inducing properties can be reliably and dose-dependently be blocked by pretreatment with selective CCK-B antagonists. Further studies are pecessary to evaluate the anxiolytic potential of CCK-B antagonists.
ASSESSMENT OF THE DESINHIBITION PHENOMENON OF THREE DOSES (1,5 - 3 AND 6 MG) OF BROMAZEPAM IN SUBJECTS WITH ANXIET PERSONALITY TRAITS

H. ALLAIN (1), V MILLET (2), J.P. MARTINET (3), P. RAOUL (4), F. LE COZ (4) L. PICHOT (2), A. LIEUAYY (5), J.-M. GANDON (4) i) Laboratoire do Pharmacologie C.H.R.U. Pontchallou, 35033 Rennes Cedex (F), (2) ROCHE, Neullly (F), (3) C.H.S.P Rennes (P), (4) BIOTRIAL SA., Drug Evaluation and Phamacology Research 20, rue Pr J Pecker, 35000 Rennes (F), (5) Laboratoire de Psychologie Expérimentale, Rennes (F). Introduction

In a previous study (1) in young healthy male volunteers (YHV), we demonstratec that the lowest doses $(1,5,3 \mathrm{mg}$ acute oral intake) of bromazepam (B) couk decrease the capacity to delay (GONNO-GO and DRL tests). The conclusion wa: that inhibition was decreased at low but not at higher dosages of $B(6 \mathrm{mg})$ in YHN According to cognitive and behavioral theories, anxiety could be preciset characterized by a blockage of action by an excess of inhibitor reactions. seemed useful to repeat the study in subjects with anxiety personality tratt (SAPT).

Aim of the study

Desinhibition induced by $B$ at 3 doses $(1,5,3$ and $6 \mathrm{mg})$ has been studied in SAP (18-30 u.o.) using a double-blind, randomized, versus placebo, double Greco-Latir square design.

Method

Sixteen (16) maie SAPT have been included in the study. Their profile has bee determined during computerized preselection tests (SILPSY from DANJOU (2)) it 150 subjects : Cattell's anxiety scale; Eysenck's personality inventory; modifier MMPI Inhibition and capacity to delay are assessed through the Logan : procedure (\% of blockades), DRL (time to count); decision test. Vigilance (CFF and divided attention were simuttaneously measured. Subjects were regularh followed-up during 8 hours, in day-time post-dosing.

Results

The results previously obtained in YHV were not reproduced in this population. Nc statistically significant results were noted on the main assessment criteria : DRI $(p=0.4709)$, GO-NO/GO $(p=0.4879), \operatorname{CFF}(p=0.4083)$ and Divided Attentior $(p=0.2439)$.

Conclusion

1. First we could discuss the sensibility of the tests used, in our population witl anxiety personality traits. 2. Low doses of $B(1.5$. to $6 \mathrm{mg})$ are inefficient it individuals with anxiety personality traits to modity the pathophysiological core $c$ this status. 3. The flexibility or reactivity of the biological systems underlyin inhibition is reduced in anxiety.

(1) ALLAIN H. et al., 9th World Congress of Psychiatry, Rio, June 1993.

(2) DANJOU Ph. et al, Therapie $1991 ; 46: 125-129$. 
Anxiolytic and antiphobic effects of antidepressants in social phobia I.M. van Vliet, J.A den Boer and H.G.M. Westenberg Department of Biological Psychiatry, Academic Hospital Utrecht P.O. Box 85500 , NL-3508 GA Utrecht, The Netherlands

Social phobia is a serious and incapacitating anxiety disorders which, in contrast to other anxiety disorders, has been little studied in psychopharmacological trial. The disorder often begins in adolescence, affecting $1-2 \%$ of the general population. Traditionally, the treatment of social phobia has been the domain of psychotherapy, but recent progress in pharmacotherapy of panic disorder has directed attention of psychopharmacologists also to social phobia. Recently, it was found that phenelzine, a nonselective and irreversible MAO inhibitor, markedly improve symptoms of social phobia. There have also been some case reports on the efficacy of other antidepressants, while $\beta$-blockers appear to be of limited therapeutic value. The latter class of compounds may relieve some somatic symptoms, but does not affect general anxiety or phobic avoidance. Apparently, the same therapeutic profile seen previously with panic disorder is now being observed with social phobial.

In this paper we will review the results of recent clinical studies on the pharmacotherapy of social phobia. We will focus primarily on controlled studies with antidepressants. In general, these studies converge to suggest that antidepressants are efficacious in social phobia. Thus, placebo controlled clinical trials with brofaromine and moclobemide, two selective MAO-A inhibitors, and a recent study with fluvoxamine, a serotonin reuptake inhibitor, indicate that these compounds are highly effective in treating symptoms of social phobia. Social anxiety is reduced gradually following chronic treatment, whereas social avoidance will mitigate also when treatment is ensued for more than 12 weeks.

These findings suggest that antidepressants, in particular those with an effect on serotonin, are effective treatments for a number of syndromes (depression, panic disorder and social phobia) with overlapping symptom clusters of which general anxiety seems to be a common denominator
TREATMENT OF REFRACTORY OBSESSTVE COMPULSIVE DISORDER Eric Hollander Department of Psychiatry, Mount Sinai school of Medicine and Queens Hospital Center, Jamaica, New York, 11432 USA

Most patients with $O C D$ can be effectively treated with specific phamacologic and behavioral approaches. Nevertheless, some patients remain refractory to standard treatments.

Camorbid Axis II disorders, such as cluster A (odd) or B (impulsive) personality disorders, social phobia, tics, neurological illness, or delusional severity may also impede treatment efficacy. Insufficient dosage, slow onset of response (12 weeks are often needed), inadequate duration of treatment (12 months is often necessary for an initial treatment length), and symptom relapse after discontinuation also need consideration.

Augmentation strategies include adding various agents to fluoxetine or SSRTs: fenfluramine $(20-60 \mathrm{mg} /$ day $)$ or desipramine $(10-30 \mathrm{mg} /$ day) for depressed $O C D$ patients: buspirone $(30-60 \mathrm{mg} /$ day) or clonazepam $(2-8 \mathrm{mg} /$ day) for anxious patients; cartamazepine $(400-1200 \mathrm{mg} / \mathrm{day})$ or lithium for bipolar or depressed $O D$ patients. When adding fluoxetine to clomipramine, follow the combined CMI and DMOMI blood levels to avoid increased risk of seizures. Intensive behavior therapy may be thought of as the first augmentation strategy for refractory $O C D$.

For other target sympton clusters, neurological damage or abnormal EEG suggest the use of an anticonvulsant; camorbid social phobia suggests an MAOI; tics Tourette's, psychotic symptoms or camorbid Axis II disorders suggest low dose high potency neuroleptic. Alternative treatments for refractory $O C D$ include MAOIs, intravenous clonipramine, antiandrogens, and neurosurgery (including capsulotony or cingulotomy).
PLACEBO-CONTROLLED STUDY OF THE ANXIOLYTIC ACTIVITY OF SINGLE DOSES OF ZACOPRIDE AMONG INPATIENTS WITH GENERALIZED ANXIETY DISORDER Antenio Gonzalez Moreno, William. Pitchot. Marc Ansseau Psychiatric Unit, C.H.U. du Sart Tilman, B-4000 Liège, Belgium

5-HT3 antagonists such as ondansetron, zacopride, and tropisetron exhibit anxiolytic potential in several animal models. The purpose of the present study was to test if single doses of zacopride possessed acute anxiolytic activity. After a complete drug-free period of at least 1 week, 14 inpatients with DSM-III-R generalized anxiety disorder (13 F, $1 \mathrm{M}$; mean age $=40.7$ years) and a Hamilton anxiety score of at least 15 (mean $=31.7 \pm 5.7$ ) received every other day single oral dose of zacopride $10 \mu \mathrm{g}, 200 \mu \mathrm{g}$, diazepam $5 \mathrm{mg}$, and placebo in a double-blind and crossover design. Assessments included Hamilton anxiety scale performed at baseline and 2 and $6 \mathrm{~h}$ later and Norris visual analogue scales completed hourly during $6 \mathrm{~h}$. Two patients did not complete the trial due to spontaneous improvement and were replaced. Statistical analysis used 3-way ANOVA (subjects, drug, sequence) with repeated measures. Results showed better anxiolytic activity of zacopride $10 \mu \mathrm{g}(\mathrm{p}=0.05)$ and diazepam $5 \mathrm{mg}(\mathrm{p}=0.02)$ compared to placebo on the Hamilton anxiety scale as well as a superiority of zacopride $10 \mu \mathrm{g}$ over placebo on 3 items of the Norris scales : troubled/tranquil, proficient/incompetent, happy/sad; a superiority of zacopride $10 \mu \mathrm{g}$ over diazepam on the item proficient/incompetent; and a superiority of diazepam over zacopride $200 \mu \mathrm{g}$ on the items attentive/dreamy and proficient/incompetent. These findings support an acute anxiolytic activity for low dose of zacopride. 